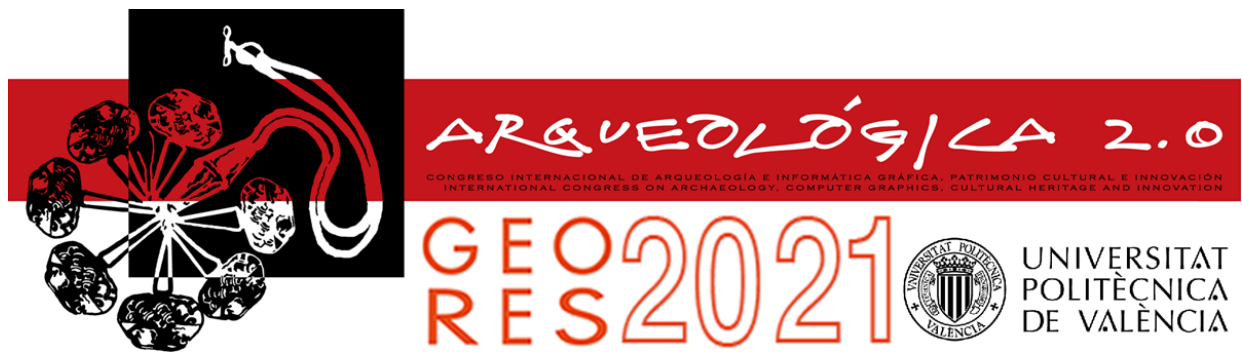

Proceedings of the joint international event $9^{\text {th }}$ ARQUEOLÓGICA

$2.0 \& 3^{\text {rd }}$ GEORES

Valencia (Spain).

26-28 April 2021

Received: 27/11/2020

Accepted: 18/03/2021

DOI: https://doi.org/10.4995/Arqueologica9.2021.12140

\title{
PARAMETRIC PARADIGMA: EXCEPTIONAL COFFERED CEILING ARCHITECTURE VS HBIM
}

\author{
Olga Rosignolia, ${ }^{\star}$, Barbara Scalab ${ }^{b}$ Daniele Treccani ${ }^{\mathrm{a}}$, Andrea Adamia $^{\mathrm{a}}$, Laura Taffurellia, Simona \\ Scandurra ${ }^{a}$, Luigi Fregonese ${ }^{a}$ \\ ${ }^{a}$ Department of Architecture, Built Environment and Construction Engineering (DABC), Politecnico di Milano, Piazza Leonardo da Vinci \\ 32, 20133 Milan, Italy. olga.rosignoli@polimi.it; daniele.treccani@polimi.it; andrea.adami@polimi.it; laura.taffurelli@polimi.it; \\ simona.scandurra@polimi.it; luigi.fregonese@polimi.it \\ ${ }^{b}$ Department of Civil, Environmental, Architectural Engineering and Mathematics (DICATAM), University of Brescia, Via Branze 43, \\ 25121 Brescia, Italy. barbara.scala@unibs.it
}

\begin{abstract}
:
The scientific community is confirming the advantages of using BIM in the processes of conservation, management, and intervention over architectural-historical heritage. However, many difficulties remain in the transcription process of elements of the built environment, especially when the objective of the model is to support decision-making processes in restoration operations. Even for apparently simple elements, the procedures are not trivial; the need to define the most adequate operational strategies remains. In the context of this study, a possible approach concerning the documentation of a coffered ceiling has been proposed, a case study which takes into consideration the need to discretize information (to make it effective, transmissible, and understandable) and the potential offered by the combined use of further software automatization.
\end{abstract}

Keywords: cultural heritage, digitization, 3D modelling, HBIM

\section{Introduction}

The parametric nature of BIM clashes greatly with the precision of the as-built acquired reality that is obtainable with nowadays digital survey techniques, especially where heritage artefacts are investigated, and the results are HBIM (Historic Building Information Modelling) products; it is almost always necessary to elaborate strategies that mediate this significant issue (Capone \& Lanzara, 2019). However, no matter how challenging the process, it is not advisable to construct an HBIM model without a precedent digital survey of the assets: the amount of knowledge obtainable with these products is indisputable, and the reason why point-clouds are the first step of the modelling process. After the survey, the socalled 'scan-to-BIM' phase follows, by means of drafting actions and modelling choices performed to recreate parametrically the geometric model from the point-cloud (Yang, Koehl, \& Grussenmeyer, 2018). This operation can be tackled differently in terms of approaches and software: methods range from automatic to semiautomatic and even manual (López, Lerones, Llamas, Gómez-García-Bermejo, \& Zalama, 2017).

Research is pushing towards reducing human manual involvement as much as possible whilst modelling heritage from digital surveys, by favouring the automatic methods. Nevertheless, the clash with the articulate and complex nature of heritage makes even this assignment challenging. Preparing a discretization of reality to be fed to automatisms is not an immediate nor an easy task itself; at the same time, excessive simplifications of the surveyed configuration, run the risk of rendering the model worthless. In between these two opposites, is possible to locate the example narrated in this paper, a case study that focuses on 3D modelling issues in HBIM practises: a $16^{\text {th }}$ century coffered ceiling.

The experience has value in that the exceptionality of the object modelled required a series of decisions that brought to the creation of an architectural 3D modelling 'paradigma': a parametric object enough coherent with the cloud as to recreate its original configuration but stripped of the geometric information related to damages and deformations.

Before narrating the experience, a few words regarding the context in which it is situated: the coffered ceiling is part of a larger HBIM project, the Duomo of Mantova: in 2018 the local Diocese required the realization of an experimental BIM model of one of its most valuable and articulated assets (the Duomo di San Pietro) for planned conservation purposes (Della Torre, 2003). The model (Fig. 1) was the result of an integrated survey (Adami et al., 2019) turned into a comprehensive digital replica, and 
the occasion on which to apply and test HBIM procedures acquired from literature.

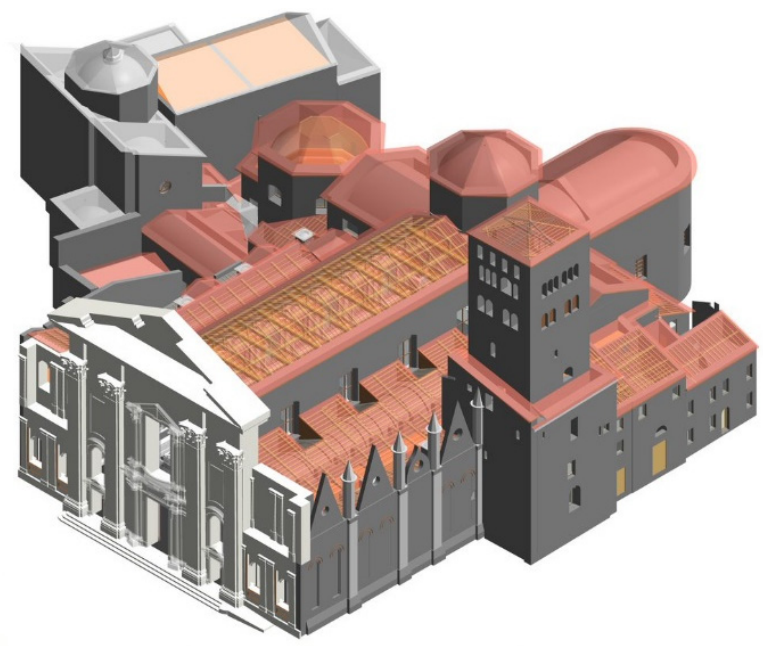

Figure 1: General outer view of the Duomo HBIM model.

The known requirements of planned conservation governed the modelling choices made (see Section 3): the presence of all the objects to schedule, their correct collocation in the three-dimensional space and their topology were the priority. Nevertheless, although some simplifications set might be considered excessive, good accuracy was obtained, given the extraordinary diversity of the Duomo (which made it impossible to have unique representation rules throughout the building). Furthermore, whenever geometry failed to describe objects adequately, informative modelling came into play to integrate what was missing as additional data.

Representation of both geometric and informative data, in an HBIM model, is rooted in the knowledge of the heritage itself (Adami et al., 2019), and its original design and functioning. This knowledge needs to be as complete as possible: archival research about the building, besides investigation about traditional techniques and materials, processes and tools used in the past for the production of artistic decorations and the training of artisans and artists, all need to come together to obtain valid description explanation of the asset.

In the Duomo, the parts that compose the coffer units were not identifiable on sight. The structural wooden pieces and the decorative wooden planks appeared as unique pieces: as it often happens for artefacts alike, the structure beneath the decorative elements had to forcibly have a different configuration from how it appeared to the naked eye as well as to the laser-scanner. With no further and more invasive analyses being planned, it was necessary to involve conservation experts which formulated hypotheses regarding the hidden technological parts. This passage was crucial, as it highlighted how the interpretation of point-clouds and survey products must be carried out by conservation experts and operators, who are the reliable sources of knowledge about historical building techniques and the devices used by artisans and artists in the past, knowledge that needs to be passed on to the model drafter.

Such knowledge is particularly important especially in cases alike: coffered ceilings, in fact, can have many different configurations, depending on the span they need to cover, the decoration required and the material available. In the case of the Duomo, the structure behaves as described in the following section.

\section{Acknowledging the exceptional technology}

The coffered ceiling was a solution technique widespread in the Mantuan cultural landscape (Introini \& Spinelli, 2018); it is also recorded that architect Giulio Romano worked at the Duomo refurbishment in the $16^{\text {th }}$ century (Piva, 1988). Other records testify the use of this technology on several churches in the area: S. Andrea Church and the Ostilia Sanctum Church are amongst the most famous. Research related to other similar cases, (even though never identical) has been used to understand thoroughly constructive functioning (Venturi, 1938; Giorgi, 2017; Antonucci, 2018).

Therefore, in the case of the coffered ceiling above the Duomo central nave, different types of knowledge, one coming from literature references (Breymann, 1884; Venturi 1938) and one provided by experts in construction techniques, were combined to the laser-scanner survey performed in the attics as well as the interior of the church (and visible in Figure 2) to understand an unprecedented artefact.

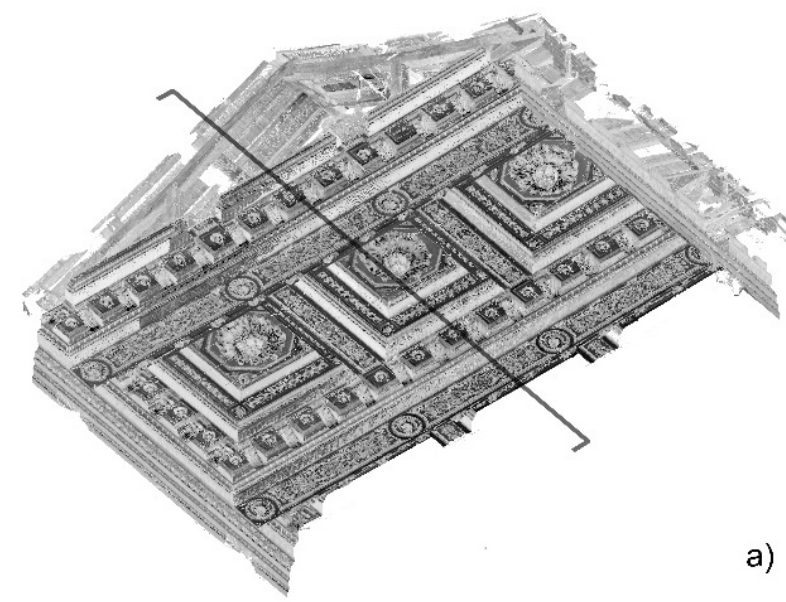

a)

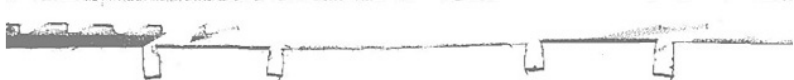

U

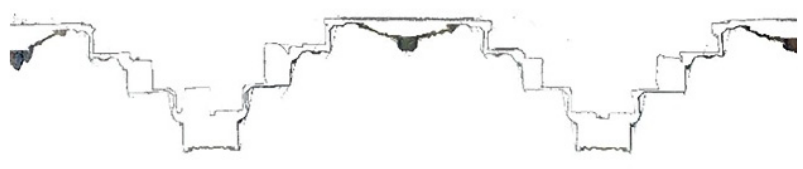

b)

Figure 2: Ceiling point-cloud. Detail of the coffer and the structure of the roof: a) axonometric view; b) longitudinal section.

During the process, it was discovered that the coffer units are hanging onto wooden trusses, which are arranged in a variable sequence. Such sequence can be described as successive pairs of trusses: some of them are of the 
Italian 'palladiana' type, whilst some others are regular trusses with additional posts (the two types are referenced as type a) or type b) in this article). The distance between the two trusses composing one pair is quite modest and occupied by smaller structural shelves (orthogonal to the truss tie beam) that themselves lean on another lower beam, situated beneath them, as visible in Figure 3.

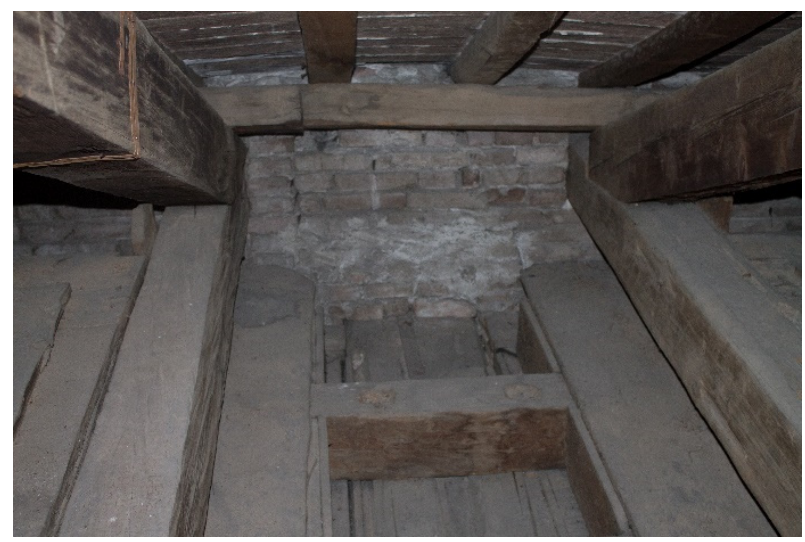

Figure 3: Photograph of the coupled trusses insertion in the perimetral walls and the shorter span between them; the upper part of the smaller structural shelves is visible.

When in the nave, it can be observed that these loadbearing elements appear as single highly decorated beams, of an unusual depth and width. The span they cover $(10 \mathrm{~m})$ guided towards adopting the hypothesis of a composite beam, fabricated of two or more jointed parts. The presence of decorated wooden planks boxes around the composite beam bottom, gives the illusion of a single element; because of that, they might be referred to as 'false beams', the Italian 'false travi' (Giorgi, 2017). To confirm this hypothesis, is the presence of metal tie rods (Fig. 4) which bear the decorative planks and are hooked to the roof purlins.

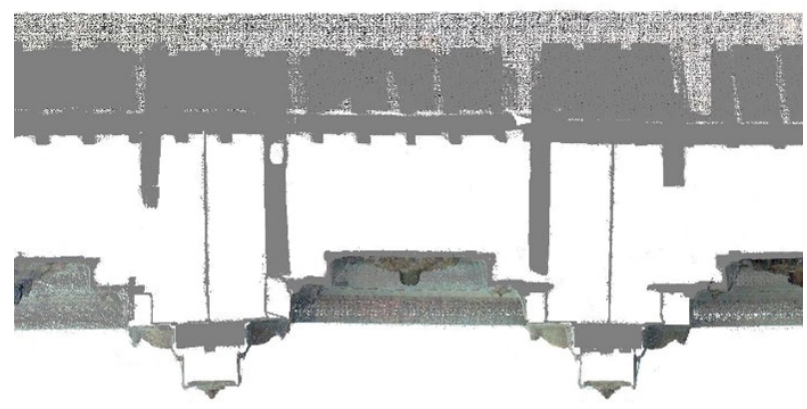

Figure 4: Longitudinal point-cloud section, the metal tie rods visible in the background.

The richness of detail visible from the nave, is the work of the ultimate layer added on to the wooden boxes, a layer composed of thinner and highly decorated planks, the socalled 'fodere'. Information from historical manuals was crucial to understand and hypothesize this detail.

The larger distance between each pair of trusses is occupied by the coffered ceiling units. Once the structural role of the beams and trusses was made clear, the technological solution used to complete the other parts of the coffers was studied. These elements are, similarly to the false beams, composed of wooden planks embedded together. Some of them encounter the trusses' tie beams perpendicularly and protrude over the nave below. Other wooden planks are positioned along the perimetral walls, visible from the nave itself but not from the attic. Their appearance is very similar to that of the composite beams described earlier.

The remaining planks, the ones holding the decorative central flower visible from the nave, have a particular spatial arrangement sequence, a stepped one. As stated before, those planks close the space between the two farther trusses pairs.

The global configuration of the technology, which is bare and discernible almost entirely when in the attic (Fig. 5), complete with the iron connections and all the devices invented by the workers to support the artistic interior decoration, is in strike contrast with the richness of the artisanal wooden work visible from the naves of the church (Fig. 6).

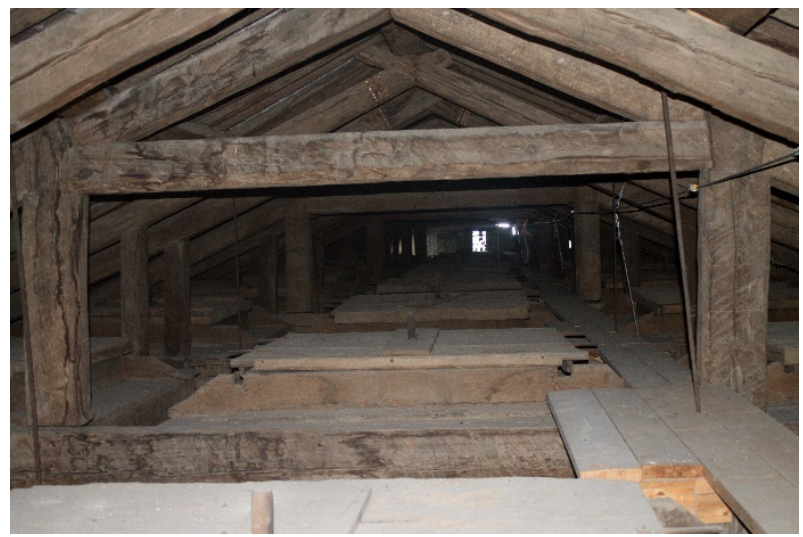

Figure 5: Photograph of the ceiling as seen from the attic; as is visible, the larger distance between the trusses is occupied by the coffer units.

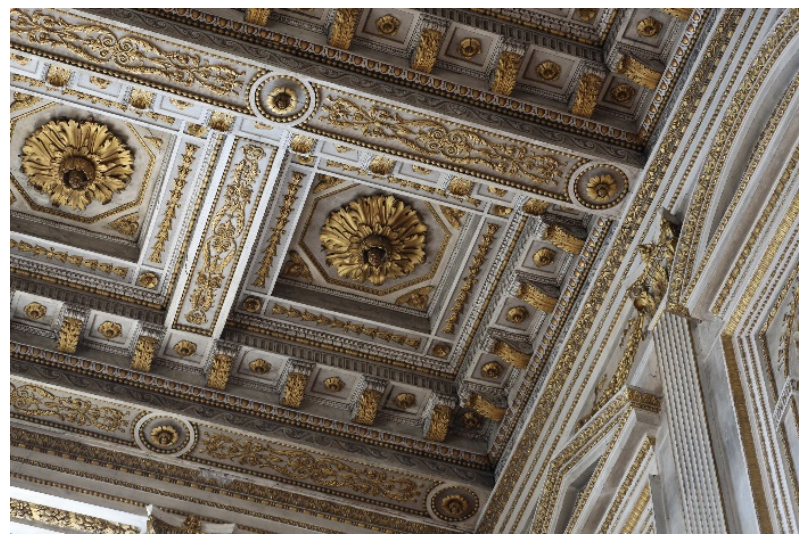

Figure 6: Photograph of the coffers as visible from the nave interior; the lower load-bearing beams are covered with decoration; the metal wire ends with the decorated circular button visible beneath the beams.

\section{Modelling choices}

The HBIM model of the Duomo was commissioned to support planned conservation activities. Given this objective and the diversity of the building (highly articulated and stratified), a general modelling rule was decided between the stakeholders: an error tolerance under $5 \mathrm{~cm}$. This rule has been tested sufficiently for what, at the beginning of the process, had been identified as a 'level of information need' in an informal way. 
The modelling process was executed with Autodesk Revit@ and Autodesk AutoCAD@.

\subsection{Semantic structure of the 3D model}

The elements of the ceiling (whose configuration is represented by the scheme in Figure 7) with structural functions, have been modelled as structural elements, to stay true to their nature and for possible further structural analysis. Given the configuration of the structure, several types of the beam are present: those composing the trusses, those at the first level (the composite beams), rafter, purlins, and the decorated planks.

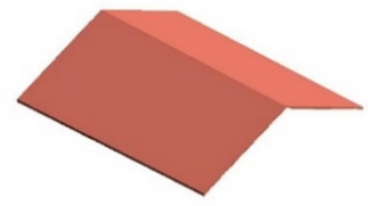

i)

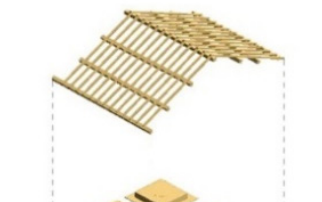

ii)

iii)

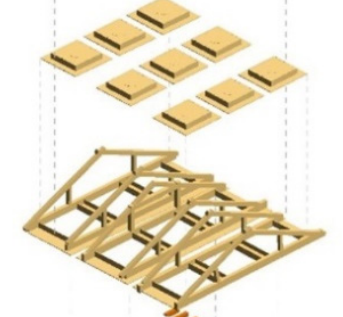

iv)
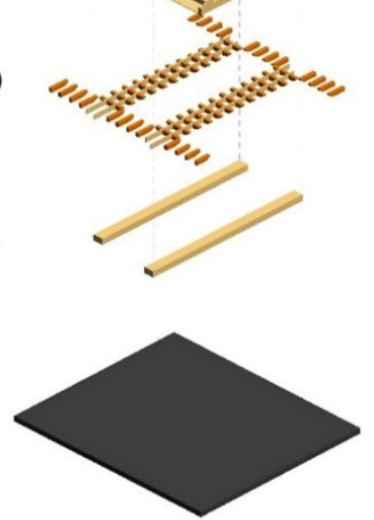

Figure 7: Model view with the ceiling parts put together from the top down: i) roof structure; ii) coffer units; iii) trusses and planks; iv) decorated shelves; v) load-bearing composite

$$
\text { beams. }
$$

The central nave coffer units are composed of numerous different planks of wood, as described in the previous section. One modelling possibility would have been to create a single element representing all the planks together; instead, when designing the object, it was preferred to draft singularly every plank element, for allowing the possibility to identify the conservative problems of the different wooden parts and of the metal wires, nails, and cramps.

These coffer units were created as 'generic' objects, as they could not be referred to any native BIM category. It is important to note that every object physically touches the others it is adjacent to. The level of decoration is significantly reduced in the model object, as it was considered not necessary to the project database (Fig. 8).
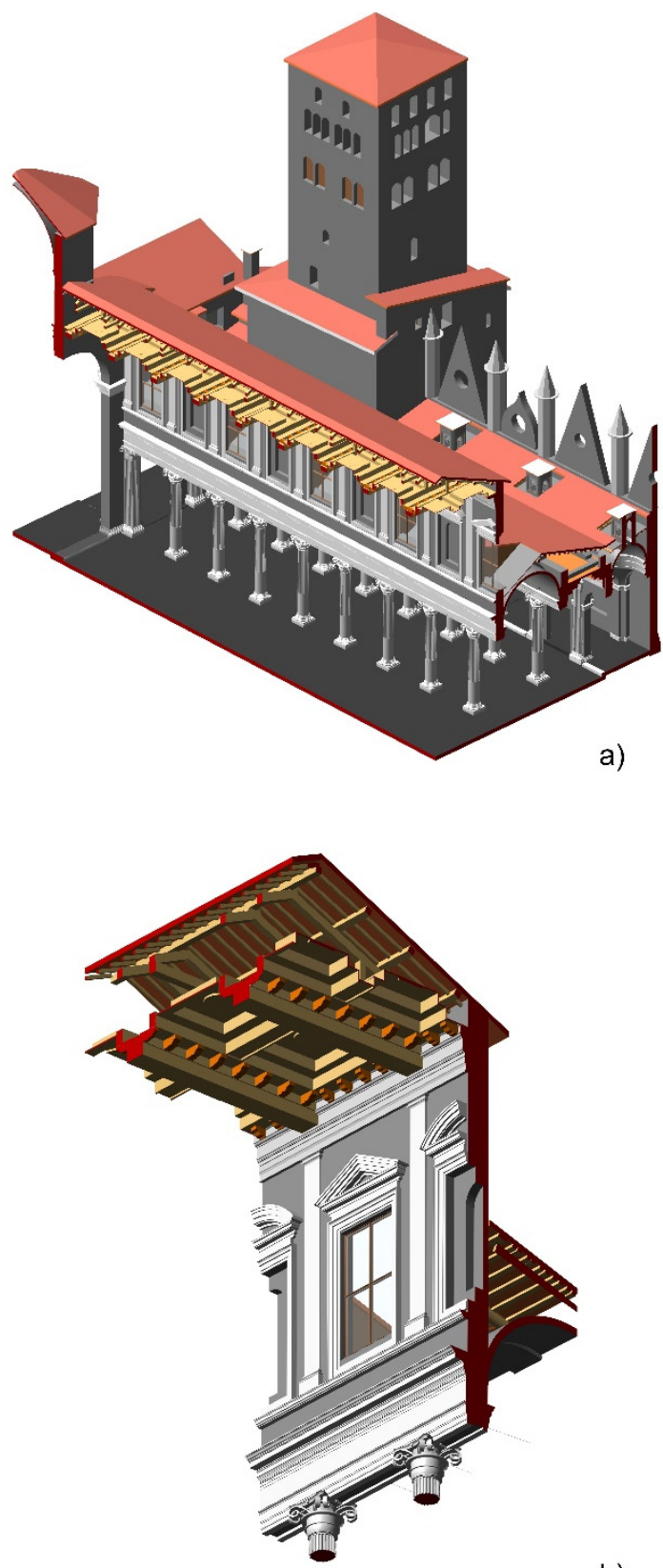

b)

Figure 8: Cut-away axonometric views of the model with the ceiling components together: a) entire ceiling; b) detail of a portion.

\subsection{Planar alignments}

Thus far, the elements used in the BIM model (except for the coffer units) were regular and functionally close to the original function (beams, rafters, purlins), therefore their category and the information included matched. At this stage, they also mainly were configured as simple regular axial extrusions. The planar layout followed strictly the information given by the point-cloud, following a nonorthogonal grid (Fig. 9). Coincidentally, the objects all laid on an ideal linear plane, including all the elements composing the trusses. 


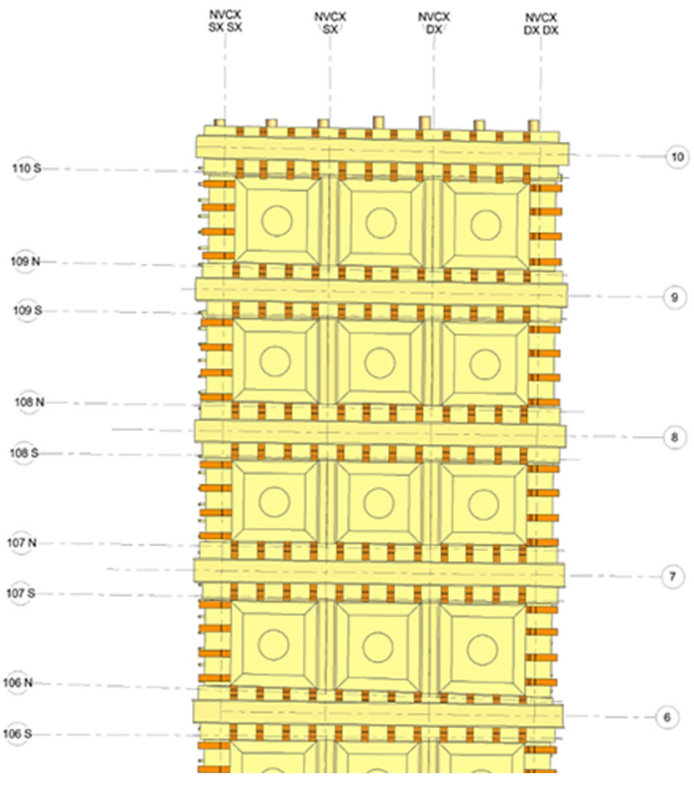

Figure 9: Planar course of the structural elements.

Other geometrical information given by the point-cloud had been harder to convey, when in elevation. The structural elements of the trusses and of the roof structure presented (as it often happens in these cases) a significative deflection at their midpoint (Fig. 10), thus determining a bended shape that influenced the dimensions of all the other components of the ceiling structure.
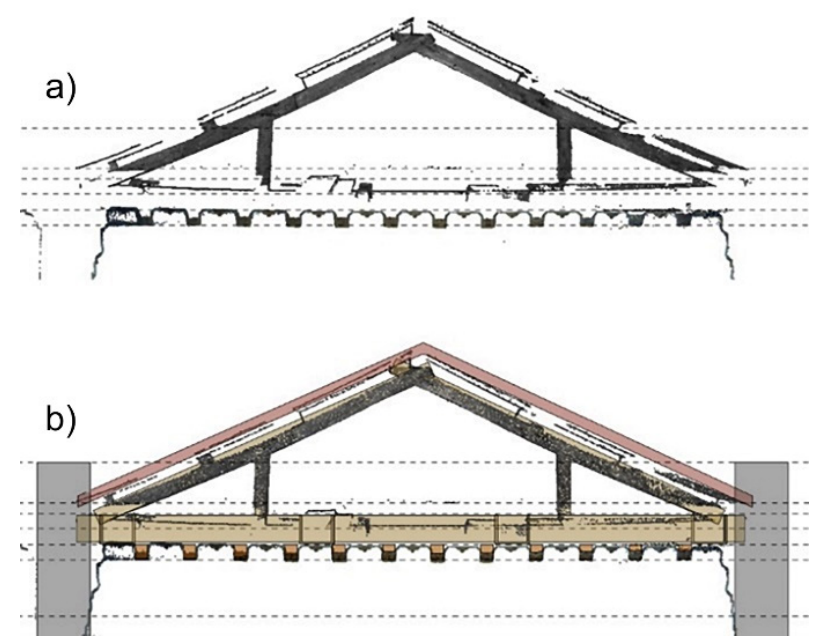

Figure 10: Example with a regular truss with additional posts ('type b' truss). Comparison between: a) point-cloud, with it is evident deflection; $b$ ) the regular objects of the model.

The deflection caused a concatenated series of other deformations: the vertical posts of type b) trusses rotated towards the exterior; the external coffers also rotated, lowering the side closer to the central axis of the nave. The central coffers do not rotate, rather lower equally on both sides; the shelves underneath the trusses tie beam also rotate around their longer axis towards the exterior.

After some observations, it was decided that the translation of these deformations in the model, could be obtained in the form of a value (namely a parameter, custom-made or default, associated to each object) more conveniently than in a geometric way, as in the example shown in Figure 11. The not equally effortless passage was the one necessary to determine the value of said parameters for each single object in the models. Manual effort would have been time-consuming; also, the quantity of the deformation parameters necessary, and their accuracy, could be defined only when different objectives, (besides the planned conservation ones) would be defined by the commission, and extremely dependent on them.

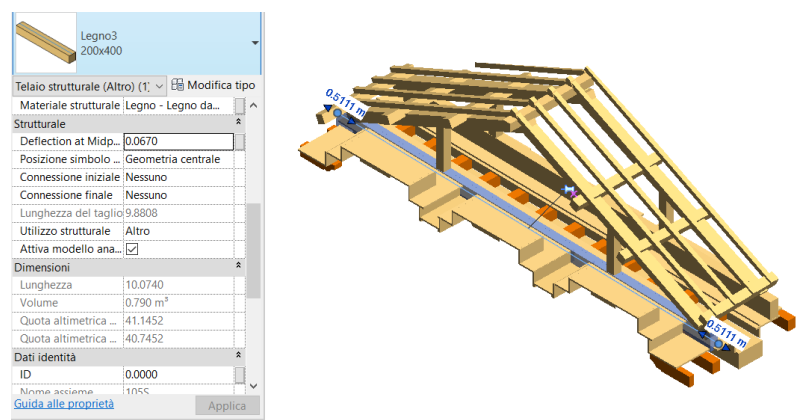

Figure 11: In the trusses there is a significant deflection at the midpoint; what could not be conveyed with the geometry was inserted as additional information, (parameter, see 'deflection at midpoint') to be compiled when necessary.

Eventually, such complexity was resolved by simplifying the geometry and not including the deformations in the model if not as addition textual values (parameters) to be compiled at a later time, as stated in the beginning. It is important to note that in the case of the trusses the deformation surpasses, in certain cases, the informal established tolerance of $5 \mathrm{~cm}$.

Therefore the HBIM model of the coffered ceiling is not as truthful to the as-built situation as the point-cloud is. It might be stated that the model, configured like this, represented the structure once it was newly built in the $16^{\text {th }}$ century, and before the loads caused the deformation of its components. This decided simplified version constitutes the 'paradigmatic' configuration of the coffered ceiling of the Duomo of Mantova.

\section{The 'paradigma' concept}

The latest research in historic architecture informative modelling displays a lot of promising possibilities that suggest the possibility of adapting geometries, even complex ones, to the very accurate data collectable in a comprehensive digital survey.

In the case of the coffered ceiling, as stated earlier, adapting the whole system to the data coming from the point-cloud elevation was challenging, even if only in determining how many deformation parameters were necessary. For the requirements of this project, geometric description of the deformations was kept aside in favour of additional parametrical information. But the premises for a future adaptation were settled by inserting some of these parameters in the model, ready to be edited when necessary. Interestingly, the recording of these value through time could also lay the groundwork for a historical record of their changes.

Once considered useful to the requirement of the project the adaptation can be performed as an additional second step. 
Otherwise, paradigmatic objects, such as the coffered ceiling in its 'static' configuration, are valuable for: documentation, simple static modelling, and even for a library of traditional architectural details. Mostly, objects alike are considered usable for future similar and therefore relatable cases (Prizeman, Pezzica, Taher, \& Boughanmi, 2020) and to possibly network the similar technologies used within the same cultural landscape.

\section{Conclusion and future works}

The exceptionality and complexity of the coffered ceiling of the Duomo (Fig. 12) highlighted an ever-present issue in the HBIM methodology process: how to and when to discretize the abundant information given by the digital survey. The manual intervention necessary to adapt or to perform adaptation automatically is an effort that is shown to be feasible: the possibility of automating operations in BIM environments arisen recently can speed up and automatize repetitive actions once executed manually (Yang, Koehl, \& Grussenmeyer, 2017). Research foresees for such tools to be used strategically to adapt complex structure in the direction of the as-built surveyed configuration. This requires a thorough knowledge of the programming languages as well as of the heritage.

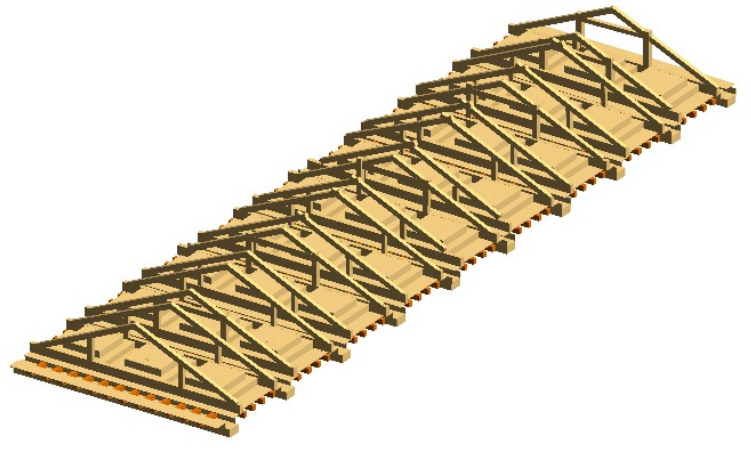

Figure 12: Axonometric view of the complete HBIM model of the coffered ceiling.

Since the routines, once performed, can be non-editable (Yang, Koehl, \& Grussenmeyer, 2018), having a paradigmatic object to which to refer to as a staple is an additional guarantee to avoid misinformation. Meanwhile, the simplified configuration ('paradigma') carries values itself: it can be easily replicated and networked, if necessary, within other buildings. Even, and more importantly, when the cases are not as exceptional.

\section{References}

Adami, A., Fregonese, L., Rosignoli, O., Scala, B., Taffurelli, L., \& Treccani, D. (2019). Geometric survey data and historical sources interpretation for HBIM process: the case of Mantua cathedral façade. ISPRS Annals of the Photogrammetry, Remote Sensing and Spatial Information Sciences, XLII-2/W11, 29-35. https://doi.org/10.5194/isprs-Archives-XLII-2-W11-29-2019

Antonucci, M. (2018). I soffitti lignei di palazzo Stati Cenci Maccarani a Roma. Opus Incertum, 3, $100-111$. https://doi.org/10.13128/opus-23054

Breymann, G. A. (1884). Costruzioni in legno. In: Trattato generale di costruzioni civili (tradotto da Carlo Valentini) 2 , Milano, Vallardi-Biblioteca Internazionale dell'Ingegnere.

Capone, M., \& Lanzara, E. (2019). Scan-to-BIM vs 3D ideal model HBIM: parametric tools to study domes geometry. ISPRS - International Archives of the Photogrammetry, Remote Sensing and Spatial Information Sciences, XLII2/W9, 219-226. https://doi.org/10.5194/isprs-archives-XLII-2-W9-219-2019

Della Torre, S. (Ed.). (2003). La conservazione programmata del patrimonio storico architettonico. Linee guida per il piano di manutenzione e consuntivo scientifico. Milano, Italy: Guerini e Associati.

Giorgi, L. (2017). I solai e i soffitti quattrocenteschi di Palazzo Vecchio, Rlcerca/REstauro, Sezione 2B: Conoscenza dell'edificio: casi-studio (Maurizio De Vita Ed.); I Convegno della Società Italiana per il Restauro dell'Architettura (SIRA), pp. 548-558. Roma, Italy: Edizioni Quasar.

Introini, M. Spinelli, L. (2018). Architettura a Mantova. Dal Palazzo Ducale alla Cartiera Burgo. Cinisello Balsamo, Italy: Silvana Editoriale.

López, F. J., Lerones, P. M., Llamas, J., Gómez-García-Bermejo, J., \& Zalama, E. (2017). A Framework for Using Point Cloud Data of Heritage Buildings Toward Geometry Modeling in A BIM Context: A Case Study on Santa Maria La Real De Mave Church. International Journal of Architectural Heritage, 11(7), 965-986. https://doi.org/10.1080/15583058.2017.1325541

Piva, P. (1988). L' "altro" Giulio Romano: il duomo di Mantova, La chiesa di Polirone e la dialettica col medioevo. Quistello, Italy, Officina Grafica Ceschi.

Prizeman, O., Pezzica, C., Taher, A., \& Boughanmi, M. (2020). Networking Historic Environmental Standards to Address Modern Challenges for Sustainable Conservation in HBIM. Applied Sciences, 10(4), 1283. https://doi.org/10.3390/app10041283

Venturi, A. (1938). Storia dell'Arte Italiana: vol XI, Architettura del Cinquecento, parte I. Milano, Italy: Edizioni Hoepli.

Yang, X., Koehl, M., \& Grussenmeyer, P. (2017). Parametric modelling of as-built beam framed structure in BIM environment. ISPRS - International Archives of the Photogrammetry, Remote Sensing and Spatial Information Sciences, XLII-2/W3, 651-657. https://doi.org/10.5194/isprs-archives-XLII-2-W3-651-2017

Yang, X., Koehl, M., \& Grussenmeyer, P. (2018). Mesh-to-bim: from segmented mesh elements to BIM model with limited 
parameters. ISPRS - International Archives of the Photogrammetry, Remote Sensing and Spatial Information Sciences, XLII-2, 1213-1218. https://doi.org/10.5194/isprs-archives-XLII-2-1213-2018 